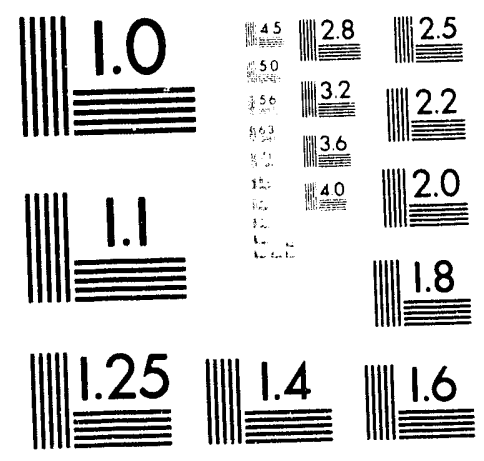



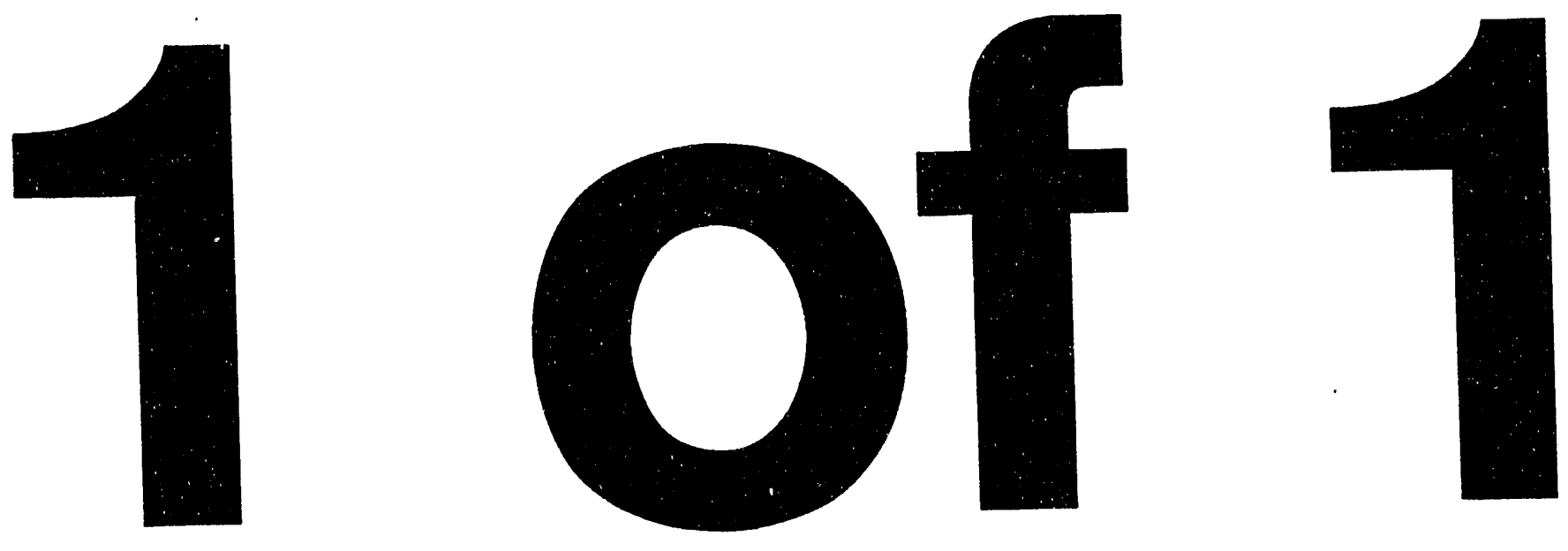


\section{PRECISE SYSTEM STABILIZATION AT SLC USING DITHER TECHNIQUES}

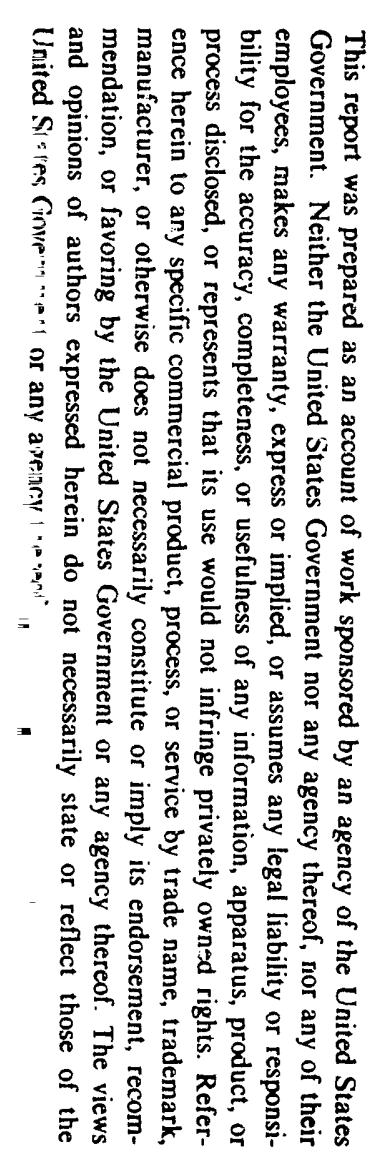

\begin{abstract}
A data acquisition method has been developed at the SLAC Linear Collider (SLC) that provides accurate beam parameter information using sub-tolerance excitation and synchronized detection. This is being applied to several SLC sub-systems to provide high speed feedback on beam paranneters such as linac output energy spread. The method has significantly improved control of the linac energy spread. The linac avcrage phase offset $(\phi)$, used to compensate the effects of longitudinal wakefields ${ }^{!}$, is adjusted \pm 1 control bil (about $0.18^{\circ} \mathrm{S}$-hand or $20 \%$ of tolerance), in a continuous fashion. Properly coordinated beam energy measurements provide a measure of the derivative of the accelerating voltage (dII/(d $\phi)$. The position of the beam on the $R F$ wave can thus be determined $10 \pm 0.3$ in about 5 seconds. The dithering does not contribute significantly to the energy jitter of the SIC and therefore does not adversely affect routine operation. Future applications include control of the interaction region heam size and orientation.
\end{abstract}

\section{Introduction}

Linear colliders require very tight control of bean parameters such as energy spread and emittance. Typical bean feedback loops in widespread use at SLC. stabilize the beam centroid to a previously recorded position or energy. Beyond this, optimization or minimization 'feedback' is required that does not restore the beam to any previous setting but instead moves it as required in order to reach an optimum as defined with respect to a uell defined signal. These loops then perform many routine tasks presently delegated to operators and the operators task becomes one of monitoring their performance.

Typical application of minimization loops is in the control of phase space volume or orientittion. Limitations in instrumentation, namely the lack of ubiquitous single pulse bean size monitors, require indirect means of measuring phase space volume. A novel technique has been tested at SLC that provides accurate control of indirectly monitored parameters through narrow band signal averaging. AI SLC, two examples of

*Work supported by Department of Energy contract DE AC03-76SFO0515. this are the average linac $R F$ phase offset, $(\phi)$, and the skew, waist and chromatic corrections applied to the interaction region beam spot.

While centroid paramelers can be easily detected and corrected locally, beam size parameters may not be correctable locally because the source of error may not be locally identifiable or correctable. However, such errors can grow and become more difficult to correct if not corrected as locally as possible ${ }^{2}$. Perhaps the most important reason for local feedback is that the transfer function between the detector and the corrector is likely $t o$ be more stable. In other words, global variables such as storage ring capture or luminosity should not be used to provide signals to loops which have controls that are far away.

At the SI,C we have applied a dither lechnique for beam size optimization. With this lechnique small changes are applied to key devices and the associated response is separately measured. The sign of the small signal response is required, in general, to indicate which way the control should be varied. The narrow band technique can be used fo reduce measurement statistical and systematic errors.

\section{Technique}

The technique is an improvement over previously established correlation procedures ${ }^{3}$ since it uses a sub-tolerance excitation and measures only the local slope. The luminosity lost in the process can be easily estimated in the case where the luminosity depends quadratically on the control.

I.el:

$S_{y}=$ the standard deviation of a single measurement of the quantity 10 minimized

$S_{\frac{\Delta y}{\Delta x}}=$ the stamdard deviation of a single dithered slope measurement

$S_{\text {ave }}=$ the standard cteviation of the average of $\mathrm{N}$ dither measurements

$S_{\text {des }}=$ desired standard deviation of averaged dither measurements

$\Delta x=$ total amount of the dither

$\mathrm{m}=$ number of beam pulses per half dither measurement (up for $m$ and down for $m$ )

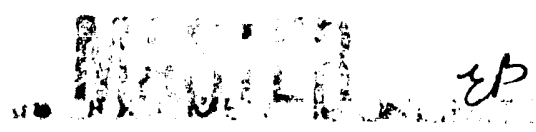

Presented at the Particle Accelerator Conference (PAC 93), Washington, DC, May 17-20, 1993 
$m=$ number of beam pulses per half dither measurement (up for $\mathrm{m}$ and down for $\mathrm{m}$ )

$N=$ number of dither measurements averaged

$f=$ repetition rate of the accelerator $(120 \mathrm{~Hz}$ for SLC)

Then the error for a single dither measurement is:

$$
S_{\frac{\Delta y}{\Delta x}}=\frac{\sqrt{2 / m} s_{y}}{D x}
$$

and the error for $\mathrm{N}$ dither measurements:

$$
S_{\text {ave }}=\sqrt{\frac{2}{\mathrm{mN}}} \frac{\mathrm{S}_{\mathrm{y}}}{\mathrm{Dx}}
$$

Total time to make a measurement of accuracy $\mathrm{S}_{\mathrm{des}}$ :

$$
\mathrm{N}=\frac{2 \mathrm{~S}_{\mathrm{y}}^{2}}{\mathrm{mS_{ \textrm {des } } ^ { 2 } \Delta \mathrm { x } ^ { 2 }}}
$$

Loss in luminosity, assuming a quadratic behavior of the luminosity around present state:
The loss in luminosity is lixed for a given desired accuracy. Using a large number of small steps or a sinall number of large steps is equivalent. This is only true for linear response. Furthermore the accuracy depends on the beam stability during the measurement.

The technique relies on the broadly based, powerful, synchronized data acquisition of the SLC control system. In the scheme adopted for this purpose, synchronizing codes are broadcast to all SLC remote data acquisition computers. The codes serve to prepare and start the sequence, guaranteeing that the control device is adjusted and the data collected on the correct pulse. Data can be acquired from throughout the complex providing a mechanism for correlation studies. In the feedback central processor, the signal is analyzed against the excitation and the response is estimated. Figure 1 shows a diagnostic, with ten times the normal excitation, used to test the system. It is clear from the figure that the nominal excitation of $0.18^{\circ}$ gives a negligible contribution to the energy jitter.

\section{Application and Results}

Table 1 lists some of the applications of minimization feedback in the SLC. The first two rows outline the average phase stabilization. We will now describe this application.

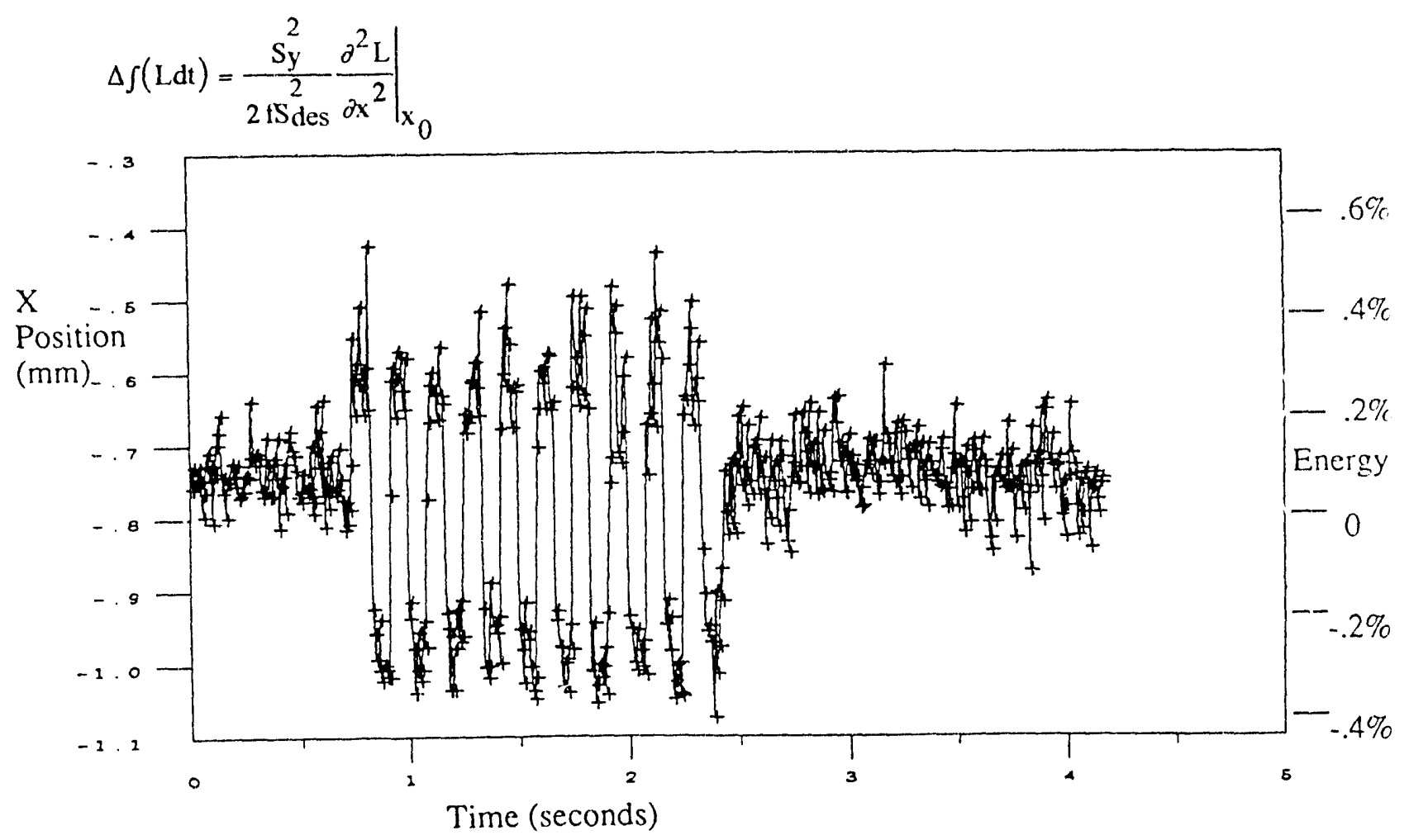

Figure 1. Energy measurements taken on 500 successive pulses showing the dither control. For this diagnostic test, the dither amplitude is 10 times the nominal $0.18^{\circ}$. 


\begin{tabular}{|c|c|c|c|c|}
\hline Iop & Method & Control & Sensor & Dither step size \\
\hline Linac $\phi$ off & $\mathrm{d}[\mathrm{d} \mathrm{d} \phi$ & Phase shifter & BPM's - high $\eta$ & $0.2^{\circ}$ \\
\hline Injector $\phi$ off & $\mathrm{dE}: / \mathrm{d} \phi$ & \begin{tabular}{|l|} 
Phase shifter \\
\end{tabular} & BPM's- high $\eta$ & 0.1 \\
\hline $\begin{array}{l}\text { Ring Extraction } \\
\text { Kicker Timing }\end{array}$ & $\begin{array}{l}\text { change in } \mathrm{x} \\
\text { correlated with } \\
\text { kicker timing }\end{array}$ & \begin{tabular}{|l|} 
Thyratron \\
trigger timing
\end{tabular} & Linac BPM's & $\begin{array}{l}\text { Nattral 'Thyratron } \\
\text { jitter, (0.1 Ins rms }\end{array}$ \\
\hline IP Waist & $\begin{array}{l}\text { Fast Luminosity } \\
\text { Monitor }\end{array}$ & $\begin{array}{l}\text { linal triplet } \\
\text { lens } \\
\end{array}$ & $\begin{array}{l}\text { Deflection angle and } \\
\text { luminosity monitor } \\
\end{array}$ & $\begin{array}{l}\text { encugh to drop } \mathrm{I} \\
\text { by } \sim 5 \%\end{array}$ \\
\hline IP Skew & $\begin{array}{l}\text { Fast Luminosity } \\
\text { Monitor }\end{array}$ & \begin{tabular}{|l}
$\begin{array}{l}\text { Skew } \\
\text { quadrupole }\end{array}$ \\
\end{tabular} & $\begin{array}{l}\text { Deflection angle and } \\
\text { luminosity monitor }\end{array}$ & $\begin{array}{l}\text { enough to drop } \mathrm{L} \\
\text { by } \sim 5 \%\end{array}$ \\
\hline IP Chromatic & $\begin{array}{l}\text { Fast Luminosity } \\
\text { Monitor } \\
\end{array}$ & Sextupoles & $\begin{array}{l}\text { Deflection angle and } \\
\text { luminosily monitor }\end{array}$ & $\begin{array}{l}\text { enough to drop } \mathrm{l} \\
\text { by } \sim 5 \%\end{array}$ \\
\hline IP Dispersion & $\begin{array}{l}\text { Fast Luminosity } \\
\text { Monitor } \\
\end{array}$ & $\begin{array}{l}\text { chromatic } \\
\text { corr. quad }\end{array}$ & $\begin{array}{l}\text { Deflection augle and } \\
\text { luminosity monitor }\end{array}$ & $\begin{array}{l}\text { enough to drop } \mathrm{L} \\
\text { hy }-5 \%\end{array}$ \\
\hline
\end{tabular}

Table 1 . The first minimization loops to be implemented at SI.C. The last 4 are an extension of existing automated interaction region (IP) luning.

The single, high peak current bunch in the SI.C linac requires strong beam loading compensation for longitudinal wakefield compensation. The slope of the accelerating RF is used for compensation with the bunch typically placed 5 to $10^{\circ}$ ahead of the crest. The energy spread and the tails of the energy spread distribution must be minimized to achieve optimum perfornance of the downstrearn chromatic corrections and to reduce detector backgrounds. The problem is that the optimum is poorly detined by the wire scans of the profile itself. Assuming constant intensity and bunch length, the optimum phase offset $\left(\phi_{0}\right)$ if $)$ constant and by determining $\phi_{0}$ ff from $\mathrm{dE} / \mathrm{d} \phi$, the derivative of energy with respect to phase we can more accurately place the bunch on the RIF. The feedback loop will dither the beam with a $30 \mathrm{~Hz}$ cycle period, \pm 1 digital to analog converter least significant bit, and apply the control at an update rate of $0.11 \mathrm{k}$. Note that for the narrow band technique, different dithering frequencies are required if multiple loops operate at once.

\section{Conclusion}

The narrow band dither lechnique will have ajplication in other machines ${ }^{4}$. It has the promise of providing accurate data that is not possible to acquire in more conventional look and adjust schemes. Ultimately, this technique may be used to remove some of the load of the operators.

\section{References}

I K. L. Bane et al., "Measurements of Longitudinal Phase Space in the SLC. Linac," Proceedings of the Second European Particle Accelerator Conference, p. $1762(1990)$.

2 J. Secman, et.al., "The Introduction of Trajectory Oscillations to Reduce Emiltance Growth in the SLC Linac', Proceedings of the $\mathrm{XV} h \mathrm{~h}$ International Conference on High Energy Acr slerators', Hamburg, 1992.

${ }_{3}^{3}$ L. Hendrickson, et.al., "The Correlation Plot facility in the SIC Control System', Proceedings of the 1991 IBIEE PAC..

4 R. Schmidt, 'Real Time Applications', Presented at the First European Workshop on Beam Instrumentation and Diagnostics for Particle Accelerators', Montreux, Switzerland, May 1993. 

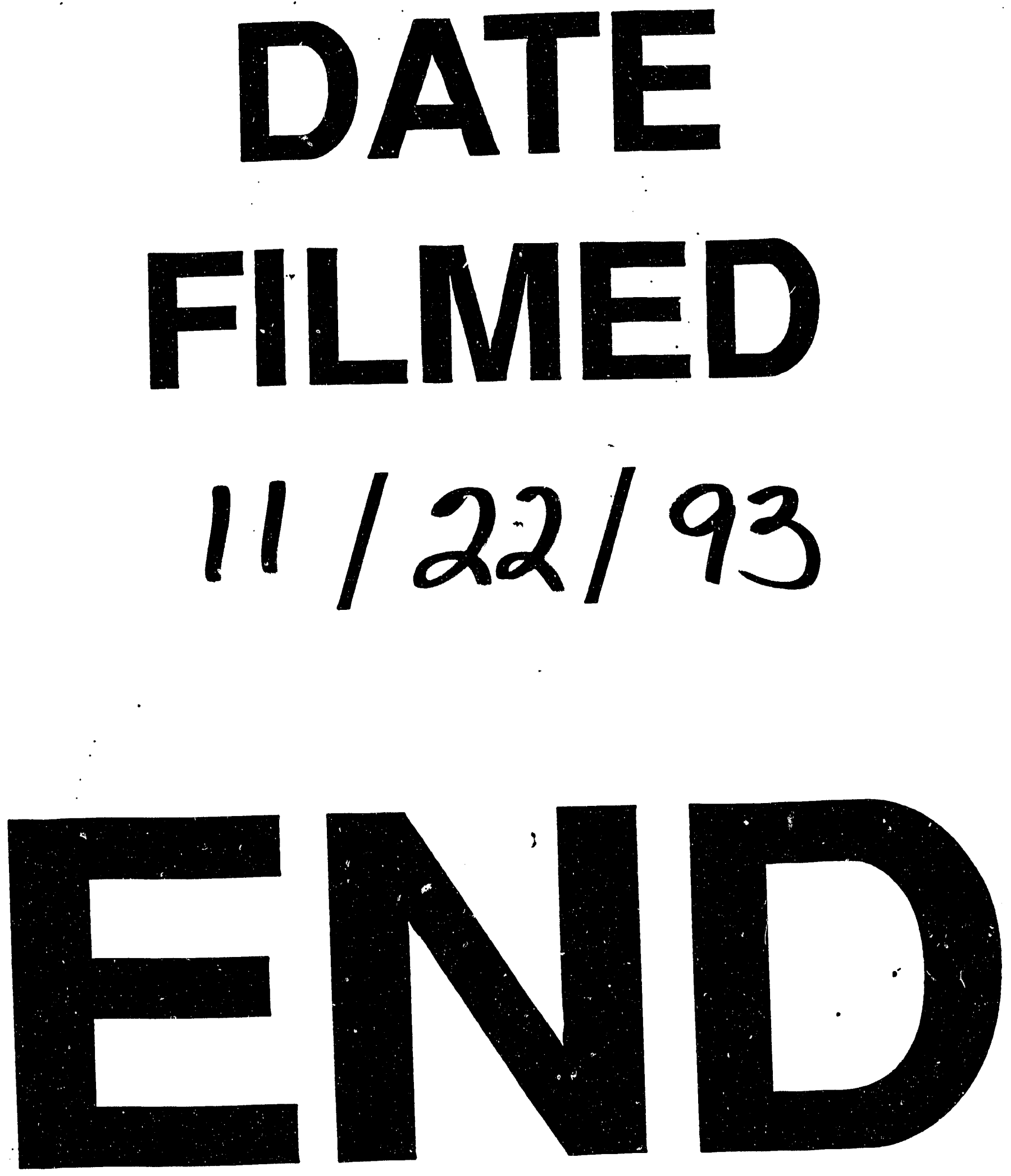
